\title{
Christine blasey ford's accusations against Brett kavanaugh: a case for discussion
}

\begin{abstract}
Accusations made by Christine Blasey Ford against Brett Kavanaugh are serious and worthy of discussion. Forensically, this presents an opportunity to pick some of the case apart to offer a better understanding of why these types of accusations are difficult to prove or disprove. Anyone can make an allegation of misconduct against someone regardless of the truthfulness of the claim. Now that this case has been in the public for some time, and we have heard from both Mrs. Ford and Mr. Kavanaugh, it is fair to examine some of the facts of the case. The intent is not to discredit Mrs. Ford or to support Mr. Kavanaugh but to examine the veracity of claims made to date. Mrs. Ford presents with several concern areas suggesting that she has been less than credible in identifying the situation of the alleged sexual assault or that Mr. Kavanaugh was in fact her assailant. Mrs. Ford appears to have engaged in therapy to retrieve memories of the incident, which raises serious problems in and of itself. She also presented with memory difficulties during the hearing and the witnesses she identified have failed to corroborate her claims. She appears credible that she was sexually assaulted, though not credible in correctly identifying or placing Mr. Kavanaugh present during the incident. In addition, she may have been the victim of multiple sexual assaults or rapes while intoxicated in high school and/or college and therefore the identification of the specific situation, location, and perpetrator may well be blurry because a single memory does not exist. Mr. Kavanaugh does not appear to present with traits or behaviors consistent with violent personality or sexual offender background and his testimony appeared credible. His strong emotional statements in both hearings appear consistent with how a wrongly accused person would respond.
\end{abstract}

Volume 7 Issue | - 2019

\author{
Scott A Johnson \\ Licensed Psychologist, Forensic Consultation, USA
}

Correspondence: Scott A Johnson, Licensed Psychologist, Forensic Consultation, USA, Tel +612-269-3628,

Emailscott@forensicconsultation.org

Received: October 25, 2018 | Published: January 04, 2019

\section{Background}

High-school and college life are both exciting and challenging, exciting because of the new freedom that adolescents and young adults now have. They can now make many more of their decisions independently and have far more decisions to make. Decisions about socializing, studying, as well as to whether to use drugs and/or alcohol. High school and college life can be challenging because with the newly found freedom and opportunities comes risks. Risks not only involving consequences for behaviors that are questionable or antisocial but the consequences of being psychologically, physically, and/or sexually assaulted or raped experimentation with drugs and alcohol is common. Many high-school and college gatherings may include alcohol and/or drugs as part of the socializing or party culture. The risk is inherent. To become intoxicated or high creates additional risks for safety. To be clear, regardless of poor or questionable decisions made, anyone who is the victim of any type of violence, (psychological, physical, or sexual) is not responsible for the perpetrator's decision and choice to engage in any type of violence. Sexual assault and rape are far too common among high-school and college students and at times may not be immediately reported. This is being written by a forensic psychologist, someone who has interviewed victims and perpetrators of sexual assault, rape, domestic abuse, child abuse, and murder, including sadists and psychopaths. This is not meant as an exhaustive literature review or exhaustive review of the case being discussed. Let us turn first to information about sexual assault and rape, recovered memories, and other background information relevant to this case.

\section{Definitions}

Sexual assault and rape may be used interchangeably for the purpose at hand. Sexual assault refers to unwanted, coerced, pressured, or forced sexual contact not involving penetration. Rape refers to unwanted, coerced, pressured, or forced sexual contact involving any type of penetration, whether oral, anal, or vaginal with any object or body part, or being forced to penetrate oneself in any fashion. Engaging in any sexual contact with someone who is impaired, whether psychologically, physically, or intoxicated/high, or passed-out/unconscious, is forced sexual contact, period. Physical force includes any type of touch, behavior, or use of weapon or objects, that could or does result in the harm to the victim. I include use of drugs and/or alcohol physical force because of the impact on the victim, making it more difficult to resist in an impaired state and unable to resist while unconscious. Psychological force includes intimidation, threats, pressure, nagging/begging, use of power or authority, emotional blackmail, or any other tactic to obtain sexual contact or to make it difficult for the victim to safely resist. ${ }^{1-3}$

\section{Prevalence of sexual assault and rape}

The prevalence of sexual assault and rape is high in our country. The literature provides consistent statistics. In summary, the literature suggests the following:

i. 1 in 4 adolescents report verbal, physical, emotional, or sexual abuse from a dating partner each year. ${ }^{4}$ About $10 \%$ of students' nationwide report being physically hurt by a boyfriend or girlfriend in the past 12 months. $^{5}$

ii. $48 \%$ of high school students reported they experienced physical aggression in their dating relationships and nearly $49 \%$ indicated they had experienced threatening behavior. ${ }^{6}$

iii. Approximately one in five female high school students (20\%) reports being physically and/or sexually abused by a dating partner (consistent from 1997 to $1999 ; 20 \%$ vs. $18 \%$ ). ${ }^{7}$ 
iv. $18-25 \%$ of women $\& 3-16 \%$ of males reported that they were the victims of Sexual Abuse, Sexual Assault or Rape by the time they graduated high school. ${ }^{8,9}$

v. In college and community samples, men's rates of self-reported rape perpetration range from $6 \%$ to $15 \%$, and rates of sexual assault perpetration range from $22 \%$ to $57 \% .^{10-15}$

vi. The rates of sexual assault of adolescents and adults have remained stable or decreasing over the last 25 years. ${ }^{9}$ The authors highlight that educational programs appear effective in preventing an increase in these rates.

vii. Less than $2-10 \%$ of all sexual assault allegations turn out to be false. ${ }^{16}$ However, to be fair, these statistics may present with problems in that they may in fact not include other data that may significantly increase the percentage of false reports. For example, the statistics may not take into account cases that were dismissed before a full investigation occurred or that involved the indicators of deception and therefore the case was dismissed due to credibility concerns. How law enforcement, high-school and college administrators, and others investigate cases can encourage false reports as well as discredit credible reports of sexual assault and rape. There are other confounding and untested factors as well that may increase the percentage. Much of the research relied on is very dated.

viii. For false child abuse/sexual abuse allegations made by others, not the victim, the percentage of false allegations may be as high as $35 \% .^{17}$

ix. It is estimated that as few as 10 percent of sexual assaults are reported to the police. The FBI estimates that only $37 \%$ of all rapes are reported to the police. U.S. Justice Department statistics are even lower, with only $26 \%$ of all rapes or attempted rapes being reported to law enforcement officials. ${ }^{18}$

\section{The violent personality}

I use the term violent personality to describe the personality and/ or traits that violent perpetrators present with (Johnson, b, pending publication). The person may not have all the following factors/traits but present with several of them. The perpetrator of sexual assault and/or rape present with what I call violent personality. Though not all sex offenders will present with all the background factors, each will present with at least several. In addition, many sex offenders, or those with violent personality, tend to offend in a variety of situations, not just in the sex offense situation. The violent personality factors and traits related sex offenses also apply to other forms of violence as well and include:
i. A history of childhood victimization
ii. attachment deficits
iii. reduced capacity for empathy
iv. witnessing parental violence
v. personality characteristics suggesting affective or cognitive deficits
vi. narcissism
vii. antisocial traits
viii. disregard for social norms

ix. tendency for aggression

x. early sexual experiences

xi. promiscuity

xii. hostility towards women

xiii. traditional views about gender roles

xiv. impulsivity, and

Xv. beliefs supporting abuse and rape

xvi. Support from others to rape is also a factor. Perpetrators often have family and friends who condone violence towards others, women or children, and support for rape.${ }^{19}$ Recall Brock Turner, the Stanford swimmer rapist, whose father commented that 20 minutes of "action" should not ruin his son's life. Interesting that the father holds rape supporting beliefs, condoning and relabeling rape as "action".

xvii. Children's exposure to domestic abuse is also correlated with negative outcomes, including psychosocial impact, which increases the chance for the children to engage in intimate partner violence later in life. Domestic abusers frequently rape their partners, again, along the continuum of violent personality, if you abuse your partner physically, you are far more likely to abuse your partner sexually

xviii. Engaging in pet abuse is also a risk factor for engaging in violence towards humans. In one study, $65 \%$ of those arrested form animal cruelty engaged in assault against another person. This is consistent with other researchers. Those who engage in animal cruelty were 3 times more likely to commit other crimes, including murder, rape, robbery, assault, harassment, threats, and drug/substance abuse.

In addition, of all 7 school shootings that occurred in the U.S. between 1997 and 2001, all of the boys had a history of engaging in animal abuse. For more of a review on the connections between pet abuse and violence towards people, see Johnson. ${ }^{19}$ Intoxication does not cause someone to sexually assault or rape. It takes a rapist to sexually assault and/or to rape. For a thorough literature review of the role of alcohol in sexual assault and rape see Johnson. ${ }^{19}$ A causal relationship between alcohol consumption and sexual assault/rape is not demonstrated given that only approximately half of the perpetrators were drinking alcohol at the time of the crime. ${ }^{10}$ The above mentioned violent personality factors may lead to the use and abuse of alcohol, which brings alcohol now into the mix as a contributing factor for sexual assault and rape, though alcohol use does not cause rape to occur. Alcohol intoxication in and of itself is not the cause of sexual assault or rape. It is unclear whether when drinking the perpetrator decides to commit the sexual assault or rape or if the perpetrator drank prior to the offense to allow an excuse or justification for the crime. Knowing that alcohol plays a role for the perpetrator in justifying and committing the rape does not lessen in any way the perpetrator's responsibility for the rape behavior (Shaver, 1987). In addition, it is impossible to know the amount of alcohol an offender consumed prior to or during the sex offense because only very few sex offenders are arrested immediately after a rape and therefore an accurate BAC (blood alcohol count or drug test) would not have been able to be administered. Remember that the primary person stating how much alcohol was consumed is the sex offender themselves and the sex offender is not considered a reliable witness of fact! One study found 
that intoxicated non-rapists were able to recognize inappropriate cues of a victim faster in an audiotaped scenario than rapists and non-rapists who had not consumed alcohol. ${ }^{20}$ The non-rapist groups presented with few if any of the above identified violent personality traits/sex offender traits and had no sex offense convictions. Although alcohol appears to increase an individual's acceptance or interest in more deviant and violent sexual situations in the laboratory, the nonrapist group demonstrated increased vigilance and were able to more quickly identify and respond to the inappropriate cues being given and not respond with further sexual arousal. This suggests that even when intoxicated, men, or at least non-rapists, have the ability to attend to inappropriate cues and cease sexual contact. Some studies suggest that the above finding may also be related to alcohol-sex expectancies when intoxicated (e.g., "when drunk, I cannot control myself"). ${ }^{21-23}$ It is also important to ask whether the intoxicated man who presents with predispositions for aggression and rape (violent personality factors/traits), why is it that they are more unable to pay attention to inappropriate cues than intoxicated non-rapists? Perhaps the intoxicated rapist perceives the inappropriate cues (e.g., victim resistance) but either simply does not care or they may enjoy the victim's suffering and resistance. The primary differences between the intoxicated male non-rapist and rapist appear to be more related to predisposition factors, alcohol myopia (although perhaps the rapist enjoys the resistance and suffering of the victim and does in fact pay attention to the victim's resistance and suffering) as well as experiential (e.g., history of sexual abuse, witnessing parental abuse), beliefs (e.g., condoning sexual assault or rape, victim blaming), and personality factors (e.g., impulsivity, narcissism, antisocial or psychopathic). See Johnson ${ }^{19}$ for a full review of this topic.

\section{PTSD}

Acute Stress Disorder and Post Traumatic Stress Disorder are common for victims of heinous events. The crimes of sexual assault and rape are included here. What is typical is that the victim experiences not only strong memories of the incident, but physiological reactions as well. That is, the victim not only remembers the incident, but their body and mind react as though the incident were occurring in real time. This creates significant impairment and distress for the victim and is often observed by others. For example, the victim is likely to withdraw from family, friends and social gatherings, and from any situation that is similar to the incident situation. They are likely to become overly startled with little provocation, have difficulty sleeping, experience depressive and anxiety symptoms, have difficulty concentrating, and may further medicate with drugs or alcohol in an ineffective attempt to stop the flashbacks and memories. What this looks like for most victims is withdrawing from others, isolating, decreased performance at school and work, and difficulty in relationships.

\section{Recovered memory therapy}

Recovered memories of sexual assault, rape and abuse are often difficult to validate given the amount of time that has past, usually years. When the memories are uncovered or made clearer within a therapy setting, the veracity of the facts becomes more unclear. In fact, therapist assisted recovered memories are often fraught with inconsistencies and the implanting of memories or supporting conclusions that are not accurate. The research, in summary, suggests that Recovered Memory Therapies often involve various levels of suggestion and contamination by the therapist. In addition, confabulation (the process of the person filling in the gaps in their memory with what seems to makers sense versus what they truly recall) now become the newly constructed memories that become the truth for the victim/patient despite not being accurate. Memories are highly susceptible to memory implantation by therapist's suggestions. ${ }^{24}$ If the therapy session is where the details came into focus, then the facts, though few at best of what happened, are highly suspect. Even the American Psychological Association recognizes that through therapy assisted recovered memories that the false construction of nonexistent abuse may surface. ${ }^{25}$ Most victims that utilized recovered memory therapy or claim repressed memory syndrome later recant their claims. This occurs because at some point they struggle with the uncertainty of what fully occurred and who the perpetrator was. The mind knows, the person can change the memory only for so long before it catches up and the memory again becomes cloudy. Consider how many people were wrongly convicted to abuse, child sexual molestation, sexual assault or rape only to have the victims state later that they are uncertain about their recovered memory and that they become aware that the perpetrator they identified was not in fact the perpetrator who harmed them. Worse yet, the victims continue to struggle with the missing memories, the pieces that still haunt them. In reality, there may be no credible memory at all of either the entire incident or of specific parts of the incident. The memory may never be recalled because it was not stored in long-term memory due to factors that include being assaulted, in a state of fight-or- flight, or unconscious.

\section{How memory works}

Simply put, memory is a fascinating and complex topic. Once in long-term memory, we do not forget. However, for victims of violent crimes, their memory may well not record and store the incident or only store part of the incident. Sometimes central features of a crime are recalled strongly while other peripheral features may not be stored at all or may have been stored with the victim recalling only blurry memory fragments. At times these fragments may be recovered, but with the caution that the apparent recollection of retrieved memory may be false (see above paragraph). Again, if the victim entered into therapy with the intention to figure out the missing incident details, the risk is high for false memories becoming the fact the victim recalls. Most victims at some point will realize this, which is understandably frustrating because they would like the full memory, the correct memory, which may never appear.

\section{How is this related to the allegations of Brett Kavanaugh?}

When examining the background of someone accused of sexual assault or rape, it is important to understand their background. A thorough assessment would include gathering records on any problem behavior, prior allegations, prior criminal convictions, as well as statements from those who have known the individual for some time or at least during a time period of concern to shed light on how the individual behaved, treated others, attachability (e.g., friendships, close family network), substance use, and other areas. Not all sex offenders will have a clear history of antisocial past, in part because if the individual was never held accountable for sexual or other violent behavior, there may be a lack of documentation for their criminal deeds. Remember that what goes on behind closed doors may never be witnessed by anyone other than a victim. Conversely, prosocial behavior may not have been witnessed by others if the individual was more of a loner, shy, inhibited, so that they may have in fact demonstrated prosocial behavior, but no one noticed. 


\section{Facts about Kavanaugh}

i. What has happened to date is that numerous individuals have made sworn statements about the prosocial behavior of Mr. Kavanaugh and only a couple of anonymous individuals say otherwise. Difficult to authenticate or believe in statements from anonymous sources, primarily because the anonymous source cannot be adequately tested or questioned to determine the veracity of their claims. Overall, Mr. Kavanaugh appears to have high degrees of morality, respect for others, and integrity for doing the right thing. There is no evidence to date to suggest that he presents with any of the above risk factors or violent personality traits. This does not mean that he is innocent, but rather that he does not present with any documented history that raises concern.

ii. His appearing judicial at one hearing was appropriate. Despite claims that this is because he knows he is guilty and getting away with sexual assault. Appearing judicial was appropriate and demonstrated his strong character. He addressed serious, humiliating claims against him. During the second hearing, he vented with anger and distain. This was also what is expected from an innocent person being crucified with falsehood. The drawback is that the democrats seized on his emotional claim of innocence as proof that he is in fact now showing his violent rapist self How untrue and unfair, no evidence to support the allegations, no witnesses, and he is guilty for behaving as any wrongly accused person should. Interesting that so many people, including over 65 women, including exgirlfriends, have testified that they never saw any of the behavior the democrats or the alleged victim claim occurred. In short, Mr. Kavanaugh's character, his personality traits, do not appear to be anything other than normal, healthy, and contradictory to how he has been portrayed in the media. It is highly likely that if he engaged in behavior such as the accused has alleged, there would likely be credible victims coming forward. To date, this has not occurred.

iii. He claims that he was a virgin in high-school. A statement that has yet to be challenged. His exgirlfriends never said anything to contradict his claims.

\section{The allegations of Christine Blasey ford}

Mrs. Ford alleges that at some party she attended when she was approximately 15 years-old, that at least two boys sexually assaulted her, with the primary perpetrator being Mr. Kavanaugh. She was vague with details until apparently engaging in recovery memory therapy in 2012. Some, not all, of the details Mrs. Ford alleges include:

i. That Kavanaugh and his friend Mark Judge allegedly held her down, groped her on the bed, and Kavanaugh allegedly covered her mouth with his hand.

ii. She claims that she was able to escape when Judge jumped on top of them and she ran to the bathroom and locked herself in. She waited until the boys had gone downstairs. She then allegedly "fled" the house.

iii. She stated that she told no one until in 2012, telling her story to her therapist. She apparently alleged to her therapist that 4 boys were involved per her therapist's notes. She stated that the therapist was erroneous in that the incident only involved 2 boys. She claims that she was in individual therapy to address a "rape attempt" in her late teens. iv. Her husband sated that she told him that two drunken boys pinned her to a bed, molested her, and he recalls her apparently mentioning Kavanaugh's name. He also recalls that she mentioned Kavanaugh's name because of her concern that he was appointed as a federal judge and that he may someday become a Supreme Court Justice and that she did not want that to happen.

v. Mark Judge, one of the original witnesses that Mrs. Ford identified, denied her account and stated that he does not recall any such incident. There were no other witnesses and again, she denies telling anyone of this until 2012.

The above taken from Brown ${ }^{26}$ the Washington Post.

\section{Concerns \& inconsistencies}

i. Mrs. Ford does not recall when and where the alleged incident occurred and has poor recall of many details. In fact, she demonstrated poor memory recall for recent events.

ii. Mrs. Ford also presented with apparent memory recall when identifying witnesses to the alleged sexual assault, all of whom have provided statements that they cannot corroborate her version of events. However, of significance is that this failed memory recall of witnesses appears to demonstrate her lack of intact, credible memories to the incident.

iii. She claims that she came to understand how that incident, a trauma, impacted her life- after being involved in psychotherapy.

iv. She indicated that she suffered academically for 4 or five years and has unhealthy relationships with men because of the alleged incident. (The above 3 taken from Brown ${ }^{26}$ the Washington Post)

v. Mrs. Ford stated that Kavanaugh and Judge left her alone when she got out of the bed and went into the bathroom, and that they never had contact again. They did not pursue her, talk with her, or attempt any further sexual contact. This is not what sexual offenders do. If in fact this was a sexual assault or attempted rape, the accused would likely have continued to pursue her or would have left the scene immediately. The men did neither.

vi. Mrs. Ford claims to have experienced difficulty in her academia. However, she appears to have continued her high school education without incident, graduating on time. She further completed her B.A. Degree in psychology at the University of North Carolina at Chapel Hill (1984-1988), completed her Doctorate in Educational Psychology from the University of California (1991-1996), a Master's Degree in Epidemiology (Biostatistics) (2007-2011), and has apparently maintained professional employment since.

vii. After entering into psychotherapy, she apparently came to the revelation, or at least her therapist's revelation, that she suffered a traumatic sexual experience in high school. She apparently experienced PTSD Symptomatology. However, that is highly unlikely. People who experience PTSD or its symptoms experience significant distress and dysfunction. Yet she appeared to complete her high school and advanced education on time. It would be helpful to see her official GPA to determine if she in fact suffered academically, which her educational record does not appear to support.

viii. If her memories of the alleged incident occurred while in psychotherapy, as she indicated, that presents with several 
concerns. As previously stated, therapist assisted recovered memories are often fraught with inconsistencies and the implanting of memories or supporting conclusions that are not accurate. Again, even the American Psychological Association recognizes that through therapy assisted recovered memories that the false construction of non-existent abuse may surface. ${ }^{25}$

ix. To date, all of Ford's identified witnesses have contradicted her statements or indicated that they did not in fact have any relevant recollection of the incident.

x. Mrs. Ford retained an attorney apparently at the recommendation of Senator Dianne Feinstein. Of concern is that victims typically want to tell their story when they come forward. They do not set demands other than for safety or anonymity. They do not retain an attorney. This dilutes the alleged victim's credibility. In fact, watching other people claim that they were victims of sexual assault or rape by perpetrators who are rich or famous help to highlight this. Those victims telling the truth did not need attorneys. Many of the alleged victims disappear from the public eye and we never hear from them again. Not because they were not being heard, they had the attention of the media but because they would likely be subjected to a polygraph exam because no evidence existed and their primary motivation was anything but justice. In fact, many that have been in the news for making such false allegations were paid to do so, again, not something that victims do. People that have been victimized do not need to be paid for coming out and telling their story. They do not need an attorney.

xi. Mrs. Ford also demanded and wanted the FBI to investigate, which can only be politically motivated. First, victim's do not request the FBI investigate their case. Victims want their case to be investigated by normal means, not the FBI. Likely a request from senator Dianne Feinstein and Mrs. Ford's attorney. Any investigation by the FBI would only delay the confirmation of Kavanaugh but never reveal the truth or untruth about the allegations. This appears highly political and not what victims demand or how they would necessarily act. Another concern is that victims do not need an attorney, only those that have something to hide, or perhaps are making false allegations to begin with. Why did she need an attorney, oh wait, that is right, she will have to give testimony under oath in front of the Senate and may perjure herself. People who have been the victim of any type of violence simply want their story told and for the perpetrator to be held accountable. She wanted neither and can never prove any of her story. In fact, the witnesses she called failed to support her claims.

xii. What is common for false or exaggerated sexual assault or rape allegations is the alleged victim adds more and more details to the story in efforts to get investigators to believe them. A genuine victim does not need to do so. They tell it like it is with the facts they know. Mrs. Ford one-ups the ante by producing witnesses that heard about the sexual assault, despite the fact she stated that she told no one. At this point, it appears most if not all of the alleged witnesses have recanted their statements and claim that they have no specific knowledge of the alleged sexual assault or of any such activity.

xiii. Ford also claims that she took a polygraph. Why? Why does a victim do this before asked to do this by investigators? This appears highly suspicious. In addition, it was not likely a polygraph that will be considered valid. For one reason, she apparently took the polygraph exam the day of or the day after (she is not clear, though a relatively recent event) attending a funeral. She was also unclear who paid for the polygraph exam, appearing confused if she did or if someone else did. Her attorneys finally admitted that they paid for the polygraph exam. No qualified or certified polygraph examiner would conduct an examination so soon following the person attending a highly traumatic and emotional event such as a funeral. In addition, the polygraph exam occurred in her hotel room, which is highly unusual. Whether the poly graph examiner followed protocol is not yet knows. Acceptable polygraphs last approximately an hour and a half to two hours.

xiv. The context of her allegations must also be taken into account. Mrs. Ford's high school was apparently a party and promiscuous sex school where people engaged in sex with anyone and then drank to forget. ${ }^{27}$ This implies that Mrs. Ford, like others at the high-school, may well have engaged in drinking, having sex, and then drinking to intoxication to forget about what they have done. She may well have been the victim of a sexual assault, or perhaps multiple sexual assaults at different parties. If there is truth to her allegation, and she experienced "PTSD" symptoms, she would have avoided subsequent parties or similar situations. This was never addressed.

xv. During her televised testimony in front of the U.S. Senate, she initially demonstrated anxiety. Her voice shaky and her eyes appearing scared, uneasy. The appearance of anxiety, fear, or tearfulness at the beginning of her testimony makes sense, but it is difficult to determine the meaning. Possible reasons for the initial anxiety and fear may include:

a. She is telling an emotionally charged and meaningful story of a painful event in her life

b. She is being questioned by the U.S. Senate about a private and painful event

c. She is on national television

d. Of course, the risk for perjury. All of these make sense.

However, after her opening statements, her voice remained stressed throughout her testimony. She appeared to lose an emotional connection to her words. Her eyes appeared unemotional, which is an unconscious, inconsistent display. It suggests that she is telling her story, presenting what in her mind are facts, but her brain not recognizing the facts, therefore, her eyes appearing unemotional because there is no true or actual memory to fit all of what she is saying. For example, she may well have been the victim of sexual assault, but her inclusion of Mr. Kavanaugh's role as the perpetrator or who was present was not clear in her memory, therefore she was not emoting to this part of her story in a manner in which we would expect to see. In essence, in consistency with her original public statements that she was not sure that Mr. Kavanaugh was in fact the perpetrator, her memory of events may have some degree of truth, but to include information obtained from recovered memory therapy recreates the event in a less than factual or accurate manner. In short, Mrs. Ford appears credible in her recollection of having been the victim of sexual assault. However, the details may never to accurately known, to her or to the public. It is common for victim, as already discussed 
above, to seek help in attempting to recover missing memories of a traumatic event. ${ }^{28}$ The problem here is inherent in the nature of memory formation and retention. First, due to the impact of alcohol, the impact of the sexual assault, and the general fight-or-flight response to an assault, the memory of a victim is generally missing some detail of the assault. For many victims, especially when they were intoxicated or unconscious, they have little or no memory of the incident. Their memory has gaps, which creates more stress for the victim. Confabulation was already discussed above. Confabulation is the process by which a person attempts to reconstruct a memory to fill in the gaps of missing information, to make the situation finally make sense. Unfortunately, as already discussed, sometimes the memory is blank in regard to certain aspects of an assault. That means, in many cases, there is no memory to recover. In the stressful struggle to make sense of the missing memory, the victim may fill in the gaps with information that appears to make sense, though not factual, as long as it makes sense the missing memory is now filled to offer a complete picture of the assault. This process is generally wrong when it comes to accuracy. In the Repressed Memory Syndrome cases of not that long ago, many victims undertook Recovered Memory Therapy and the process involved most therapists implanting or suggesting facts to the victim that made sense but were the therapist's interpretations not the victim's genuine memory. The therapists also contaminated the victim's memory of an assault by directly or indirectly supporting the wrong details for the victim or by interpreting for the victim what occurred. ${ }^{29}$

In short, Mrs. Ford's recollection of Mr. Kavanaugh being the perpetrator remains highly suspect given her memory impairment demonstrated in previous statements as well as her experiencing memory difficulty about recent events.

Mr. Kavanaugh now being the perpetrator in Mrs. Ford's mind becomes the new filled-in memory, to which she has little emotion about him specifically, and her claim of being $100 \%$ certain is more likely a saving face statement, that she cannot now back down. In addition, changing the perpetrator, who was unknown for so many years to Mr. Kavanaugh is reassuring to her to finally have a full picture of what happened, despite this likely being a therapy induced identification.

People argue, "She has nothing to gain from her reporting of the incident". Really, what about the book deal? Can no one really see the possible secondary gain for Mrs. Ford, She is a California psychologist at a well-respected university who will likely get a book deal and perhaps a movie deal; all form an ambiguous sexual assault claim. Reasons for why Mrs. Ford may confidently state that Mr. Kavanaugh was in the perpetrator may well include:

i. She now truly believes that he is the perpetrator after years without a clear picture of the incident perhaps due to recovered memory therapy.

ii. She now has a lot to lose if she recants.

iii. Pressure from others, especially the democrats for naming Mr. Kavanaugh.

iv. The threat to her own sanity if she admits that she cannot clearly identify Mr. Kavanaugh as her perpetrator, the memory again being blank.

v. Confabulation that involves it simply must have been him, despite all of her alleged witnesses contradicting her. vi. Possibly that Mr. Kavanaugh, in her mind and in the mind of others, represents the individual who commits sexual assault and rape and gets away with it. Mr. Kavanaugh now becomes the poster child for all victims of sexual assault and rape for victims who never received justice, at the expense of Mr. Kavanaugh's reputation, career, and family. So then to falsely accuse Mr. Kavanaugh sends a powerful message to all perpetrators that they will at some point be held accountable.

vii. Another possibility is that given the socializing that occurred in high-school that apparently focused on drinking, promiscuous sex, and then drinking to forget, that she was the victim over the years of multiple sexual assaults and possibly even rapes. If so, she may not have a single, focused memory of the multiple incidents or of specific perpetrators. This would be understandable for the victim of multiple sexual assaults/rapes. If this is the case, that would explain why Mrs. Ford cannot describe accurately any specific party or location of where the alleged sexual assault at hand took place, was unable to identify Mr. Kavanaugh as the perpetrator at the time or even so very many years later, as well as to why people she stated were present or knew about it, were never there and knew nothing about it.

viii. If the situation described above ( $\mathrm{g}$ ) is the case, then identifying Mr. Kavanaugh may well have been a nefarious identification, giving only facts that are blurry and facts that are not able to be substantiated, and to prevent Mr. Kavanaugh from ever being appointed to the U.S. Supreme Court. It was not until he was apparently elected as a federal judge that Mrs. Kavanaugh identified him as the perpetrator and/or around the time she sought therapy to help retrieve the memory (Recovered Memory Therapy- again, not likely to produce a valid memory but rather to contaminate or create a memory that really does not exist). It is high suspect that her identification came about at the time of Mr. Kavanaugh's appointment as a federal judge. People at that time apparently had concerns about Mr. Kavanaugh concerning his views on abortion and other issues, and the Democrats did not support him. Mrs. Kavanaugh is a Democrat and teaching at a prestigious California College. Just expressing possible other motivations. ${ }^{30}$

\section{The political motivations}

There is so very much wrong with the political narrative of this case. The timing of the allegation being made public was obvious ploys at derailing Mr. Kavanaugh's appointment to the Supreme Court, mostly because he was appointed by President trump. Several questions appear appropriate to be addressed here. Again, this is not an exhaustive list of questions but some that need to be addressed. The questions include:

a. Why Senator Dianne Feinstein waited for nearly two months before disclosing the allegation? This should have been disclosed immediately. Her delayed response clearly suggests the lack of seriousness the Democrats gave this allegation and appeared to use it solely as a last resort to sabotage Mr. Kavanaugh's confirmation (political motivation).

b. Democrat's women's rights groups yell that everyone should believe Mrs. Ford and stop the nomination process of Mr. Kavanaugh, the Democrats successfully stalling the process. However, what about Keith Ellison, the Minnesota Senator 
accused of domestic abuse. The Democrats blatantly disregard Mr. Ellison's victim's allegations and vowed to isolate and threaten her. In that case, there apparently were records of the alleged abuse. What a double standard when it comes to a republican. Democrats care little for the rights and protection of women unless it appears to fit into their narrative at that time.

c. The democrats want nothing but to declare Mr. Kavanaugh guilty, despite the blurry facts and how Mrs. Ford came to identify Mr. Kavanaugh as the perpetrator. This, despite not holding democrats accountable for domestic abuse. Interesting political play, which is wrought with bias and injustice? The motivation is nefarious and damaging to our country as well as to people who have been victims of sexual assault and rape who can clearly identify their perpetrator

d. The Democrats take it further to state that "men with penises" are biased against victims and of course commit sexual assault and rape. What about the democrat males? Interesting dilemma that somehow democrat males are exempt from the above analogy. And being male does not make every male a rapist. What a ridiculous argument.

e. In the end, Mr. Kavanaugh appears to be the democrat's poster child representing all men who commit sexual assault despite no evidence that he is guilty. $\mathrm{He}$ is the representation of all perpetrators of sexual assault and rape to be crucified for all victims who never had justice. Despite it being false justice, despite no evidence that is credible, he is deemed guilty to prove a political point. He has become the Democrats representation all men who engaged in sexual assault and rape that attended elite schools, again without any accurate or compelling evidence. ${ }^{31}$

\section{Difficulties in this case for investigation}

In determining credibility, especially for allegations involving an incident that occurred over 35 years ago, is nothing short of a difficult and challenging endeavor. He said/she said is all you have. No documentation about the incident was made at the time of the alleged incident, and no one was told until so many years later. Both Mrs. Ford and Mr. Cavanaugh appear credible. However, as discussed above, Mrs. Ford's recollections, actions, and statements, as well as her utilizing recovered memory therapy, cast shadows of doubt over her version of what occurred. No doubt that something occurred, no doubt that she believes that she was a victim, but critical details were missing that most victims would have recalled. Victims of any crime will need to be questioned to get their version of what occurred. At times, interrogation techniques are used to ensure that the victim is accurately and consistently reporting facts. It is also important to assess the validity of recovered memories of sexual abuse and rape. The research is clear that most recovered memories are not fully valid in that whatever the missing details were, that were later recovered, tend not to be factual. Confabulation, therapist contamination, friends and family contaminating the victim's version of the incident, and of course, the victim's desire and struggle to put the pieces together create difficulty assessing truth from fiction.

\section{Why did the Senators choose to question Mrs. Ford and Mr. Cavanaugh but chose to utilize a female prosecutor to conduct the interview?}

This was a damn if you do and damn if you don't scenario. If the Senators ask the questions themselves, most being men, it appears that they are bullying the alleged victim. If they use the female prosecutor, it may give the impression that they are attacking the alleged victim. The prosecutor is experienced in asking questions to get to the truth and to clarify what the alleged victim is stating. All in all, however, the choice to use a female prosecutor was the most effective and gentle approach. There was simply no nice way to conduct the interview. In addition, the Democrats repeatedly bashed male Senators for engaging in any questioning of Mrs. Ford, even though they too have male Senators who would participate.

\section{Why did the victim's name get leaked to the press?}

It was understood, and no one has challenged, that the victim wanted to remain anonymous. Yet someone from the democrat side leaked the information. This forced Mrs. Ford to have to address the issue and allegations in a highly public, politicized arena. And yet it is the same Democrats that claim that any questioning of Mrs. Ford is simply an attack on her. They forced the public hand, and the Senate had no choice but to question her. Again, a damn if you do and damn if you don't situation. Where was the respect for Mrs. Ford to remain confidential? And then there is the question of lying. Confabulation is not a blatant lie and should not be condemning for a victim. Confabulation is the victim's way of filling in missing pieces of a stressful and dangerous attack. On the other hand, if Kavanaugh lied about what the definitions were in his high school yearbook or whether he ever drank to intoxication that would not be significant either. He is damned no matter how he answers. If he admits to ever drinking to intoxication, the Democrats will seize on that as proof he is a rapist and drank so much he forgot the offense. Also, being intoxicated on occasion is not the same as proving that he made intoxication a regular part of his socializing behaviour. He is being accused of a crime that he insists did not occur, that he did not perpetrate the heinous crime of sexual assault. Emotions run high, anger is high, and fear is high. Fear for the innocent person, which appears to fit Mr. Kavanaugh, includes fear for his family, his reputation, and the general embarrassment that occurs when being falsely accused for both understandable and forgivable. The extreme stress on Mr. Kavanaugh, who claims his innocence, is unimaginable unless you have been also been accused of something heinous, though many people have been the victims of false allegations and can relate. Perhaps the question is "does anyone have anything that they have lied or been less than honest about in their entire life?" Of course, everyone must answer that they have lied at some point or have been less than forthcoming of the facts. Now compound that with what an innocent person experiences when wrongly accused of a heinous crime, it is easier to understand that some small lie may occur simply out of the frustration of the entire process and the emotional, physical, personal, and spiritual toll taken. Even if Mr. Kavanaugh lied about the meaning of terms in his yearbook, at that point in the hearing his frustration and anger level would be completely understandable and insignificant about his character under normal circumstances. Even if in the heat of the moment, again, a highly charged victimizing process for an innocent man, lying may serve to address the damned if he does and damned if he doesn't conflict. In addition, accusers may come out of the woodwork to get their 5 minutes of fame. To date, no credible additional victim has been identified. No one without dubious motivations, have come forward. In fact, just the opposite. Women have spoken loud and clear that Mr. Kavanaugh was never known to engage in such violent behavior nor that he has ever been accused of such behavior in the past Difficult task determining credibility at this point, not really. If Mr. Kavanaugh were a sexual assaulter or 
rapist, other credible victims would have come out by now, and his assaultive behavior would very likely have continued not ceased. Yet over 65 women, some exgirlfriends, colleagues, and others, strongly assert that they have never been aware of Mr. Kavanaugh engaging in sexual harassment, sexual assault, rape, or abuse. It is always important to believe a victim when they first make their claim. However, false allegations occur at a higher rate than ever before in today's politically charged environment. "Fuzzy" details should never be treated as factual. Victims may be telling partial or full truths, but it is important to take into consideration what the victim's version of the incident is missing. Although there is truth to what most victims allege, recovered memories are a dangerous dilemma. Much of the time it is impossible to determine the full truth. That does not mean prosecute someone based on partial truths. Those that take the stand that partial or fuzzy memories are enough to prove guilt or innocence are simply not fairly judging the incident with justice in mind. It is not acceptable to claim someone is guilty of a sex offense unless the evidence is strong, not relying solely or strongly on recovered memories.

\section{What information do we need?}

I. We need to see the high school, college, and graduate college transcripts to determine if Mrs. Ford did, in fact, suffer academic problems following the alleged incident.

II. Mr. Kavanaugh's and Mrs. Judge's behavior of leaving Mrs. Ford alone when she went into the bathroom is not consistent with how sex offenders would likely behave. They would be more likely to either flee the situation or pursue their victim. Neither happened. Why?

III. In her successful life, how has she been negatively impacted? Aside from her claimed sexual or intimacy difficulties with men, which if true, may or may not have anything to do with Mr. Kavanaugh, what other relationships suffered prior to or following the alleged incident? Apparently, she participated in the high school drinking and promiscuity parties and again, completed her education on time.

IV. Her claimed PTSD symptoms and apparent recollection of recovered memory of the incident following psychotherapy is suspect. If the therapist is a psychoanalytic based therapist, then the theoretical belief is that all of life's problems and anxiety stems from sexual and abuse problems. So, there is the fishing trip. In addition, repressed and recovered memories are always suspect. They are seriously at risk for contamination by a therapist (even more so if hypnosis or narco-therapy is used). Confabulation is also a serious complicating factor, that is, creating the missing memory to fit either what makes sense or creates memories to fit into a narrative. Regardless, recovered memories pose a serious problem in that they are nearly impossible to prove or disprove and are generally found to be unreliable. More information is needed about her "therapy" process.

V. We only have her husband's word that she mentioned Mr. Kavanaugh's name in 2005. The veracity of his claim is obvioushe is her husband and would likely be biased in supporting her case. Was he polygraphed and if not, why?

VI. Who administered the polygraph? Was it by someone currently certified to administer and interpret a polygraph exam? Was the polygraph administered per protocol, lasting at least an hour and a half? And again, why did the polygraph occur in the first place? It apparently was given in Mrs. Ford's hotel room following a funeral.

VII. A further assessment of Mrs. Ford's mental confusion and memory problems that she appears to present with. She experienced difficulty recalling recent events, such as where and when the polygraph exam took place, who paid for the polygraph exam, and whether she sent a summary, or all of her therapy notes to the newspaper.

\section{Information for victims}

This case does not represent a typical scenario for sexual assault and rape victims. This case was highly political from the start and made public. The typical victim has memories of what occurred, at least some stable memories. Details may be foggy, but victims telling the truth do not need recovery memory therapy- they just need people to listen and support them in telling their story. It is important for victims to take care of their immediate emotional and physical needs. A victim should never be shamed for not following these recommendations but encouraged to do so. These are some suggestions.

a. Always tell others what happened. A friend, family member, rape or victim advocate, or a therapist.

b. If possible, seek medical attention as soon as possible and before changing clothes or showering to preserve evidence.

c. Contact campus security, campus police, and always contact local law enforcement. It is important to make an official record of the incident as soon as possible. Even if reported to a school official or campus police, report to local police as well. Have a friend or family member come with for support if needed.

d. Even if the victim does not want to press charges, tell others including the police. Give a victim interview so that the incident is documented. The victim may change their mind later and the report that was given as close to the time of the incident holds more power than one given months or years later.

e. It is ok for a victim to say "I don't recall all of the details" of the incident. No one expects them to do so, especially immediately following the incident. However, as the victim hears themselves reporting the details, more details come into focus.

f. Victims who were drugged or unconscious at the time of the incident may not realize that they were in fact victimized. Once a sexual assault or rape is suspected, do the above.

g. Seek medical treatment for their own protection. This includes testing for any sexually transmitted infections/viruses, pregnancy, as well as for injury. Seek mental health support as well from a victim advocate.

h. Despite the feelings of anger, shame, confusion, embarrassment, fear, and many other emotions, encourage the victim to talk about the incident. Give support, the secondary trauma is keeping the incident private.

i. Do not let this case, or any other public case for that matter, discourage the victim from reporting the incident. Remember that few cases are as politically motivated as the current case and rarely are the victim's name or specifics of the incident made public. What is seen in the media, such as this case, are highly politicized and fuzzy cases that never should have been made 
public. Most of these types of cases, in fact, turn out not to be credible. The victim does not need an attorney to report the crime and they do not have to be on television or the news. In the highprofile cases we have seen in recent years, most allegations were false from the beginning and therefore should not be compared to victims reporting actual sexual assaults or rapes.

\section{Summary}

In summary, alleged victims should always be believed until there is evidence not to. In most cases of reported domestic abuse, sexual assault, rape, sexual harassment, and stalking, supporting facts and details often surface to lend credibility to the allegations. In this case, not only is the timing of the blurry allegations a concern, but the use of recovered memory via therapy, which is always problematic in a court of law because the process allows for contamination by the therapist and confabulation on the part of the patient. Mr. Kavanaugh should not be politically used as the poster boy for victims who never had justice. Victims want their perpetrator held accountable, not someone else. The facts of allegations in this case are do not appear credible. Mrs. Ford was very likely the victim of one or more sexual assaults or rapes, given the party history disclosed in the media. But to falsely accuse the wrong person is unacceptable. It should be noted that there are additional facts that have proven inconsistent as well which have not been discussed above. This is a politically charged case that never should have made it into the media. Democrats chose to reveal the victim's name against her wishes, forcing her into a no- win situation of having to strongly standby her accusations, despite likely blurriness of the facts. Everything she describes about the offense situation, location, dates, and witnesses, have not supported her accusations against Mr. Kavanaugh. Victims should always be believed, that is important and true, until evidence suggests that the credibility of the facts or alleged victim become suspicious. It is important as well to identify conflicting motivations by the alleged victim and by those supporting the victim, in this case, her attorney and the Democrats. Sexual assault and rape should never be used as a political pawn. Mrs. Ford and Mr. Kavanaugh have experienced victimization by the process itself. Mrs. Ford appears to have been used as a political pawn in that she was forced to attest to facts that she clearly was uncertain about (again, see previous statements she made prior to the hearings). Mr. Kavanaugh was used as a political pawn because he was elected into the Supreme Court by President Trump as well as to apparently serve as a symbolic rapist for all victims who have not received justice. Cases like this present with so many problematic aspects. Victim recall, witnesses that contradict the victim's version of the incident, blurry memory, incomplete memory, victims with current memory difficulty, retrieved memory therapy, politicization of the case, case being made public or being tried in public opinion, and of course, the lack of any tangible or credible evidence all present with complications when assessing the veracity of claims. In most sexual assault and rape situations, the politicization, details being leaked to the public via media and extensive media coverage are not present which helps with maintaining a confidential and safe environment for he alleged victim.

\section{Acknowledgments}

None.

\section{Conflicts of interest}

The author declares that there are no conflicts of interest.

\section{References}

1. Johnson SA. Psychological Force in Sexual Abuse: Implications for Recovery. In: Schwartz BK, Cellini HR, editors. The Sex Offender. New Insights, Treatment Innovations and Legal Developments. Civic Research Institute. 1997;17-11.

2. Johnson SA. An Overlooked Factor in Sexual Abuse: Psychological and Physical Force Examined. Journal of Offender Rehabilitation. 1998;28(1):141-151.

3. Johnson SA. Psychological Force in Sexual Offenses: Forensic and Treatment Implications. In: Schwartz BK, editor. Handbook of Sex Offender Treatment. Civic Research Institute. 2011;28:28.

4. Foshee VA, Linder GF, Bauman KE, et al. The Safe Dates project theoretical basis, evaluation design, and selected baseline findings. American Journal of Preventive Medicine. 1996;12(5):39-47.

5. Centers for Disease Control and Prevention. Youth Risk Behavioural Surveillance-United States, 2009. MMWR 2010.

6. Jouriles EN, McDonald R, Garrido E, et al. Assessing Aggression in Adolescent Romantic Relationships: Can We Do It Better? Psychological Assessment. 2005;17(4):469-475.

7. Silverman JG, Raj A, Mucci LA, et al. Dating violence against adolescent girls and associated substance use, unhealthy weight control, sexual risk behaviour, pregnancy, and suicidality. Journal of the American Medical Association. 2000;286(5):572-579.

8. Finkelhor D, Hotaling G, Lewis IA, et al. Sexual abuse in a national survey of adult men and women: Prevalence, characteristics and risk factors. Child Abuse \& Neglect.1990;14:19-28.

9. Finkelhor D, Gewirtz-Meydan A. 18\% of Teen Girls are Sexually Assaulted but Few Report it; Can Education Help? The Conversation. 2018.

10. Abbey A, McAuslan P, Ross LT. Sexual assault perpetration by college men: The role of alcohol, misperception of sexual intent, and sexual beliefs and experiences. Journal of Social and Clinical Psychology. 1998;17(2):167-195.

11. Calhoun KC, Bernat JA, Clum GA, et al. Sexual coercion and attraction to sexual aggression in a community sample of young men. Journal of Interpersonal Violence. 1997;12(3):392-406.

12. Muehlenhard CL, Linton MA. Date rape and sexual aggression in dating situations: Incidence and risk factors. Journal of Counseling Psychology. 1987;34(2):186-196.

13. Rapaport K, Burkhart BR. Personality and attitudinal characteristics of sexually coercive college males. Journal of Abnormal Psychology. 1984;93(2):216-221

14. Senn CY, Desmarais S, Vernberg N, et al. Predicting coercive sexual behaviour across the lifespan in a random sample of Canadian men. Journal of Social and Personal Relationships. 2000;17(1):95-113.

15. White JW, Smith PH. Violence Against Women: Identifying Risk Factors. Research in Brief. National Institute of Justice. 2004.

16. Lonsway KA, Archambault J, Lisak D. False Reports: Moving Beyond the Issue to Successfully Investigate and Prosecute Non-Stranger Sexual Assault. The Voice. 2009.

17. Trocmé N, Bala N. False allegations of abuse and neglect when parents separate. Child Abuse \& Neglect. 2005;29(12):1333-1345.

18. Tjaden P, Thoennes N. Extent, Nature, and Consequences of Rape Victimization: Findings from the National Violence Against Women Survey. Special Report. National Institute of Justice and the Centers for Disease Control and Prevention. 2006. 
19. Johnson SA. Intoxicated Perpetrators of Sexual Assault \& Rape Know What they are Doing despite Intoxication: What the Literature Has to Say. Journal of Forensic Sciences \& Criminal Investigation. 2017;1(4):555-570.

20. Wydra A, Marshall WL, Earls CM, et al. Identification of cues and control of sexual arousal by rapists. Behaviour Research and Therapy, $1983 ; 21(5): 469-476$.

21. George WH, Dermen KH, Nochajski TH. Expectancy set, self-reported expectancies and predispositional traits: Predicting interest in violence and erotica. Journal of Studies on Alcohol. 1989;50:541-551.

22. George WH, Marlatt GA. The effects of alcohol and anger on interes in violence, erotica, and deviance. Journal of Abnormal Psychology. 1986;95:150-158.

23. McMurran M, Bellfield H. Sex-related alcohol expectancies in rapists. Criminal Behaviour and Mental Health. 1993;3:76-84.

24. Loftus EF. Creating false memories. Scientific American. 1997;277(3):70-75.

25. Fletcher C. Repressed Memories: Do Triggering Methods Contribute to Witness Testimony Reliability? Washington University Journal of Law \& Policy. 2003;13:335-356.
26. Brown E. California professor, writer of confidential Brett Kavanaugh letter, speaks out about her allegation of sexual assault. The Washington Post. 2018.

27. CHQ Staff. Bombshell: Christine Blasey Ford's Hidden High School Social Life. Richard Viguerie's Conservative HQ. 2018.

28. Emsdorff GM, Loflus EF. Let Sleeping Memories Lie? Words of Caution about Tolling the Statute of Limitations in Cases of Memory Repression. Journal of Criminal Law \& Criminology. 1993;84(1):129-174.

29. Johnson SA. Animal Cruelty, Pet Abuse \& Violence: The Missed Dangerous Connection. Journal of Forensic Sciences \& Criminal Investigation. 2018.

30. Johnson SA. Campus Rape \& Sexual Assault Explored: An Educational Summary of the Problem. Journal of Criminology and Forensic studies. 2018;1(2).

31. Koss MP, Gidycz CA, Wisniewski N. The scope of rape: Incidence and prevalence of sexual aggression and victimization in a national sample of higher education students. Journal of Consulting and Clinical Psychology. 1987;55(2):162-170. 